\title{
DEFINING A META-DESIGN FRAMEWORK FOR KNITTING THE EMERGENT CITY ELEMENTS
}

\author{
Author(s) / Auteur(s) : \\ Antonio OPROMOLLA ${ }^{1,2}$ \\ ${ }^{I}$ PhD Student in Interaction Design \\ ISIA Roma Design \\ ${ }^{2}$ Research Assistant \\ Link Campus University, Rome \\ anto.opro@gmail.com \\ Valentina VOLPI, ${ }^{1,2}$ \\ ${ }^{1}$ PhD Student in Interaction Design \\ ISIA Roma Design \\ ${ }^{2}$ Research Assistant \\ Link Campus University, Rome \\ valentina.volpi84@gmail.com
}

Roberta GRIMALDI ${ }^{1,2}$

${ }^{1}$ PhD Student in Interaction Design

ISIA Roma Design

${ }^{2}$ Research Assistant

Link Campus University, Rome

robertagrim@gmail.com

Mauro PALATUCCI

Professor in Interaction Design

ISIA Roma Design

mauro.palatucci@gmail.com

Carlo Maria MEDAGLIA

Head of Research Department

Link Campus University, Rome

c.medaglia@unilink.it

\section{Keywords / Mots-clés :}

processes of emergence, re-semantization of places, city boundaries, social behaviours, Calvino, meta-design, city images,

\section{SOME EXAMPLES OF EMERGENT PROPERTIES IN THE URBAN ENVIRONMENT}

The environmental transformations of the city are the expression of processes of emergence in social systems that continuously redefine the city as a system (Minati, 2001).

In detail, in a previous study, we identified and illustrated three examples to show how the city evolves on the basis of the emergent properties: the re-semantization of specific city elements; the 
boundary conditions as source of system change; the social behaviours and interactions as soft protests (Volpi et al., 2015).

The first consists in the attribution of a new meaning to urban ecosystem elements (Martinelli, 2004) as the result of the wear process of the relations between subjects and objects that make up the city. Social or individual actions produce new meanings, by redefining and re-establishing relationships, or altering old ones. An example is the use of elements of the urban furniture for a function other than which they were designed for.

The second is about the "boundary" as both a barrier to the change of the system (so a disabling element for it), and a bridge to it (so an enabling element for its development). This allows to overcome the vision of the "center" as the core of the system in contrast to the suburb areas as a fringe of the system, referring not only to the spatial conditions, but to the topics of political and media agendas, too. The new proprieties of the boundary reach the center, originating fusion, contamination, innovation, and opportunities. This process is the outcome of individual or collective actions that aim to add these new properties to the system identity. An example of these observations are the French riots occurred in 2005 in the banlieu, when the discontent of the Arab, North African, and black French second generation immigrants suddenly exploded.

The third focuses on some social behaviors and relationships among the city users that indicate a dysfunction of the city. These attitudes represent a collective intelligence applied to the city to resolve common criticalities, assuming the form of a soft protest. Their aim is to show an alternative solution for better living the city. Some of these collective actions redefine the social interaction on the basis of mutual support and sharing "philosophy". An example is the practice of ticket crossing, that spread from Nord Europe to Italy as early as 2011.

These occurrences are "traces" only apparently separated. Indeed, since these single elements are part of a more complex system, they can be reciprocally linked into "knitted" patterns.

\section{THE EMERGENT PROPERTIES AS "IMAGES" OF THE CITY BORROWED FROM CALVINO'S WORK}

As a progression of our study, in this paper we intend to systematize the process of interpretation of the city illustrated above, making a further step forward in the "knitting of the traces". In detail, starting from the acknowledgment of the complexity of the city as a system, we try to categorize the processes of emergence previously identified on the basis of the attributes sprang from the study of the process itself. We sustain this step through the correlation of the emergent properties of each identified process with the representations of the different cities coming from the work "Le città invisibili" by Italo Calvino (Calvino, 1996).

In this novel, Calvino defines some general attributes of the cities (e.g.: tradings, eyes, thin, etc.) and for each of them he identifies some specific declensions, inventing about sixty imaginary cities.

The three examples of processes of emergence discussed above can be the expression of three different cities of Calvino's novel. In details, the process of re-semantization of city elements can be intended as an element belonging to a "city of memory" called Zaira, that consists of "[...] relationships between the measurements of its space and the events of its past. [...] A description of Zaira as it is today should contain all of Zaira's past. The city, however, does not tell its past, but 
contains it like the lines of a hand, written in the corners of the streets, the gratings of the windows [...]".

The boundary conditions can be intended as a process belonging to a "hidden city" called Olinda, in which "the old walls expand bearing the old quarters with them, enlarged but maintaining their proportions an a broader horizon at the edges of the city; they surround the slightly newer quarters, which also grew up on the margins and became thinner to make room for still more recent ones pressing from inside". In Olinda the center conceals the new that develops in concentric circles from the inside to the outside, overtaking the traditional meaning of boundary.

The social behaviours and interactions as soft protests can be intended as processes of a "trading city" called Ersilia, in which "[...] to establish the relationships that sustain the city's life, the inhabitants stretch strings from the corners of the houses, white or black or gray or black-and-white according to whether they mark a relationship of blood, of trade, authority, agency. [...] Ersilia's refugees look at the labyrinth of taut strings and poles that rise in the plain. That is the city of Ersilia still, and they are nothing".

Then, we went further in the abstraction and simplification of the identified attributes by choosing a single image exemplifying a single attribute. In these three cities, a specific image is provided: Zaira is an hand, with its line of the memory; Olinda is a set of concentric circles in which the boundary is a bridge to the change; and Ersilia is a set of twisted wires of the relationship between citizen.

\section{IDENTIFYING INTERACTION PATTERNS AMONG EMERGENT PROPERTIES}

In a real context, a single city is not defined by one single attribute (or one of its declensions), but by a large set of them. As well as the Calvino's invisible cities are an (extreme) expression of a single attribute even if they are essentially part of one city.

So, we need to analyse the complexity of a city considering the interactions among this large set of attributes and then of more processes of emergence at the same time. Indeed, by putting in relation one or more specific images of the city attributes (or declensions) and then exploring their possible interaction patterns, we provide a way to recompose the complexity of the city by knitting the traces.

If the identified processes of emergence were part of a single city regarded as a system, the hand, the concentric circles, and the twisted wires have to interact. In effect, according to Minati (Minati, 2011), the interaction among elements is a necessary condition to qualify them as a system. Considering that, it is necessary to find one (or more) representation that describe the possible patterns of interaction between two or more images. In our case: how an hand can interact with concentric circles or twisted wires?

According to the Generative Design approach ${ }^{1}$ and thanks to an open source 3D graphics and animation software, we have built an animation to simulate how these three attributes, as expressed through images, could interact.

Then we can see the interaction: the hand, with its past memories (showed through the resemantization of the urban elements), links to the other hands creating the twisted wires, actually the

\footnotetext{
1 "Generative Design is a morphogenetic process using algorithms structured as not-linear systems for endless unique and unrepeatable results performed by an idea-code" (Soddu, 1992).
} 
relationships. And through this network of relationships the processes of emergence can spread their action through concentric circles.

By the interaction of these three images, we noticed that every image can be related to the others and it can express different emergence processes. Moreover, to this level of observation, the hand may represent the action (e.g. the change), the twisted wires the channels on which it moves, and the concentric circles the mode of diffusion. The Figure 1 shows an example of this interaction process.
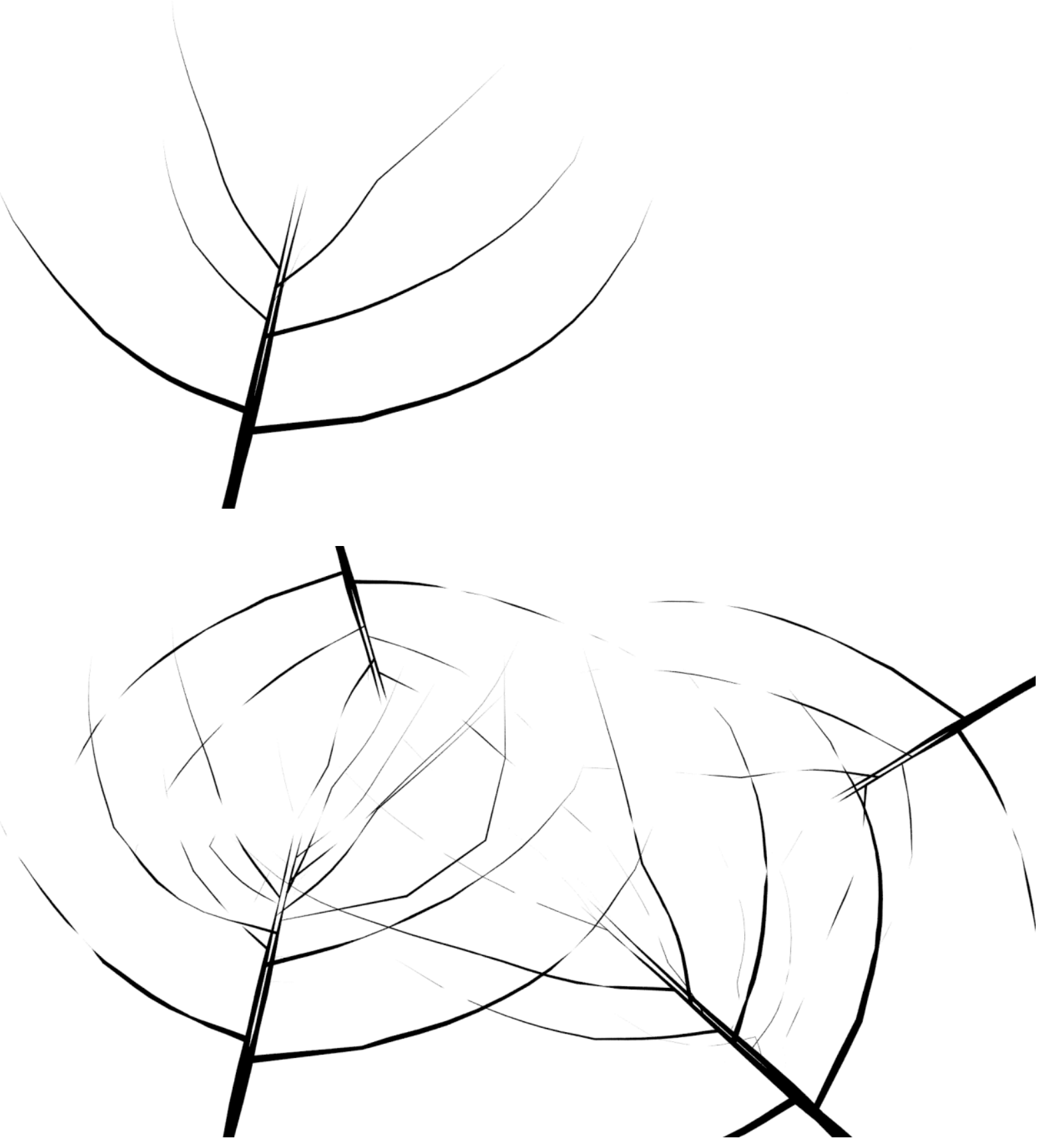


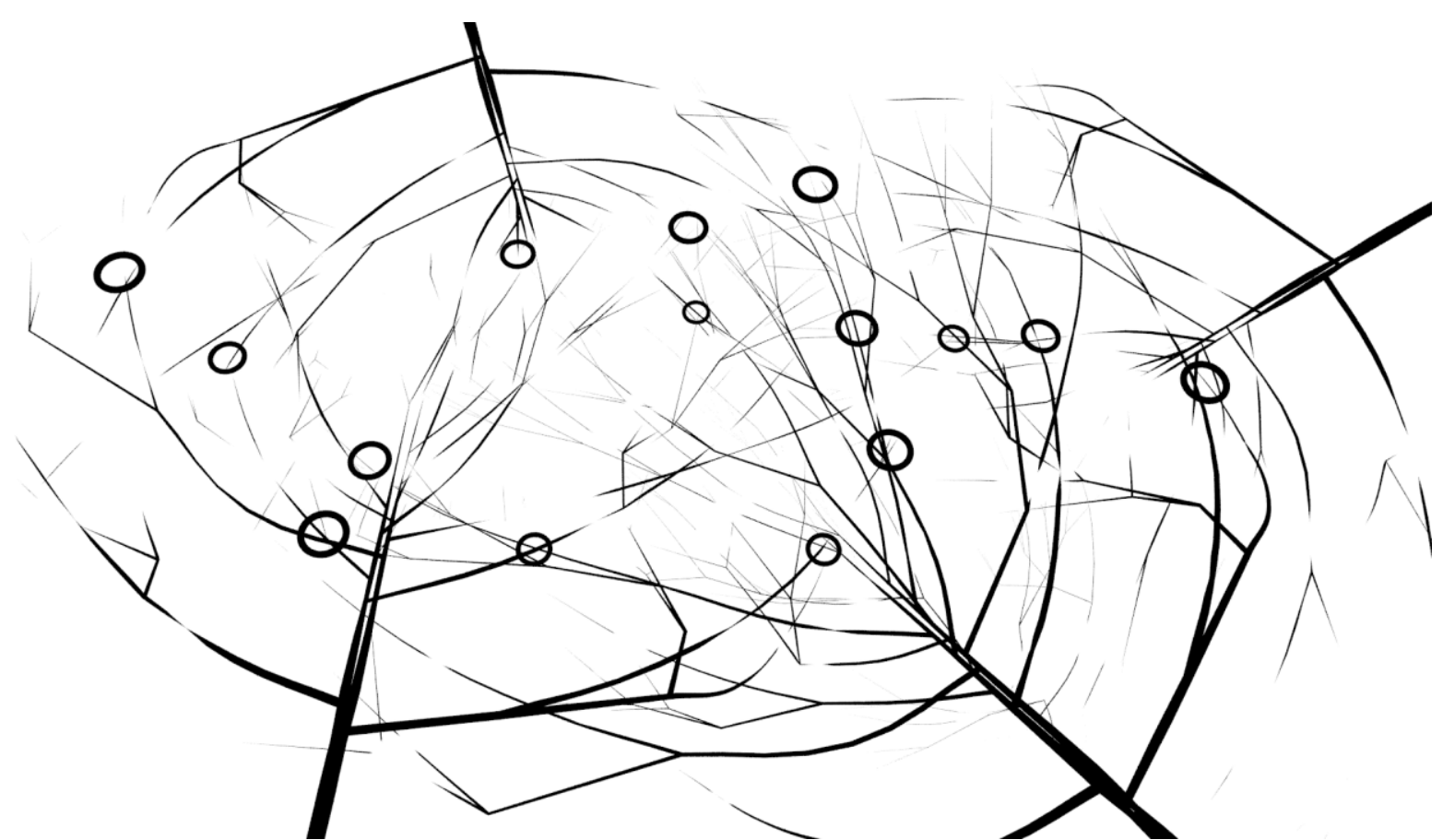

Figure 1. At the beginning of the process there are the hand lines that traces the past memories of the city. Then, by linking different hand lines, the twisted wires emerge. From the intersections of the emerged network of relationships some local actions spread and they expand themselves through concentric circles, overcoming local boundaries and showing the whole complex system.

\section{A META-DESIGN FRAMEWORK AS APPROACH TO COMPLEXITY}

Extended to other interactions patterns and images, this exercise at knitting the traces can offer a flexible meta-design framework for managing the complexity of the city regarded as a system. We do not produce a model. We prefigured a tool not directly applicable, but that gives an approach to complexity. Through this approach we figure out the interactions among emergent elements of the city.

In detail, after synthesizing the identified emergent processes of the city through the visualization of an image containing the main features of the processes related to the city aspects, we recompose them into a storytelling describing how the processes could interact together and affect the city development dynamics.

Schematically the approach we suggest has 5 different levels of thinking (Figure 2):

1. Reality Level: at this stage the designers observe the complexity of reality, the processes of emergence and their expression modes. In our example we have focused on emerging identity elements expressed through environmental transformation of the city.

2. Emergent Process Level: this stage consists of the formalization of the identified processes. In our case we had three emergent properties: the re-semantization of specific city elements; the boundary conditions as source of system change; the social behaviours and interactions as soft protests.

3. Deconstructing Level: at this stage the designers analyse and characterize the identified emergent processes. As described above, we focused on three aspects, i.e. past memories, boundary, and relationship. 
4. Visualization Level: at this stage the designers figure out the attributes just identified. In our case we have found in three of the imaginary cities of Calvino a perfect correspondence with the attributes. 5. Interaction Storytelling Level: this level aims to knitting the traces making to interact the chosen images. This level allows to identify the categories of the elements, in order to design solutions that take advantage of these specific interactions. In our example this stage was made possible thanks to a 3D animation software and an underlying approach of Generative Design. It should be considered as a simple tool for the interaction storytelling level. Designers can choose the most suitable tool for this level, according to their skills and to the characteristics of the processes identified. The focus at this stage is the resulting storytelling, not how we build it.

Furthermore, we have to clarify that the interaction pattern described above is one of the possible combination in terms of interaction storytelling. It is possible to combine them differently or in new ways, according to meta-design attitude we suggest.

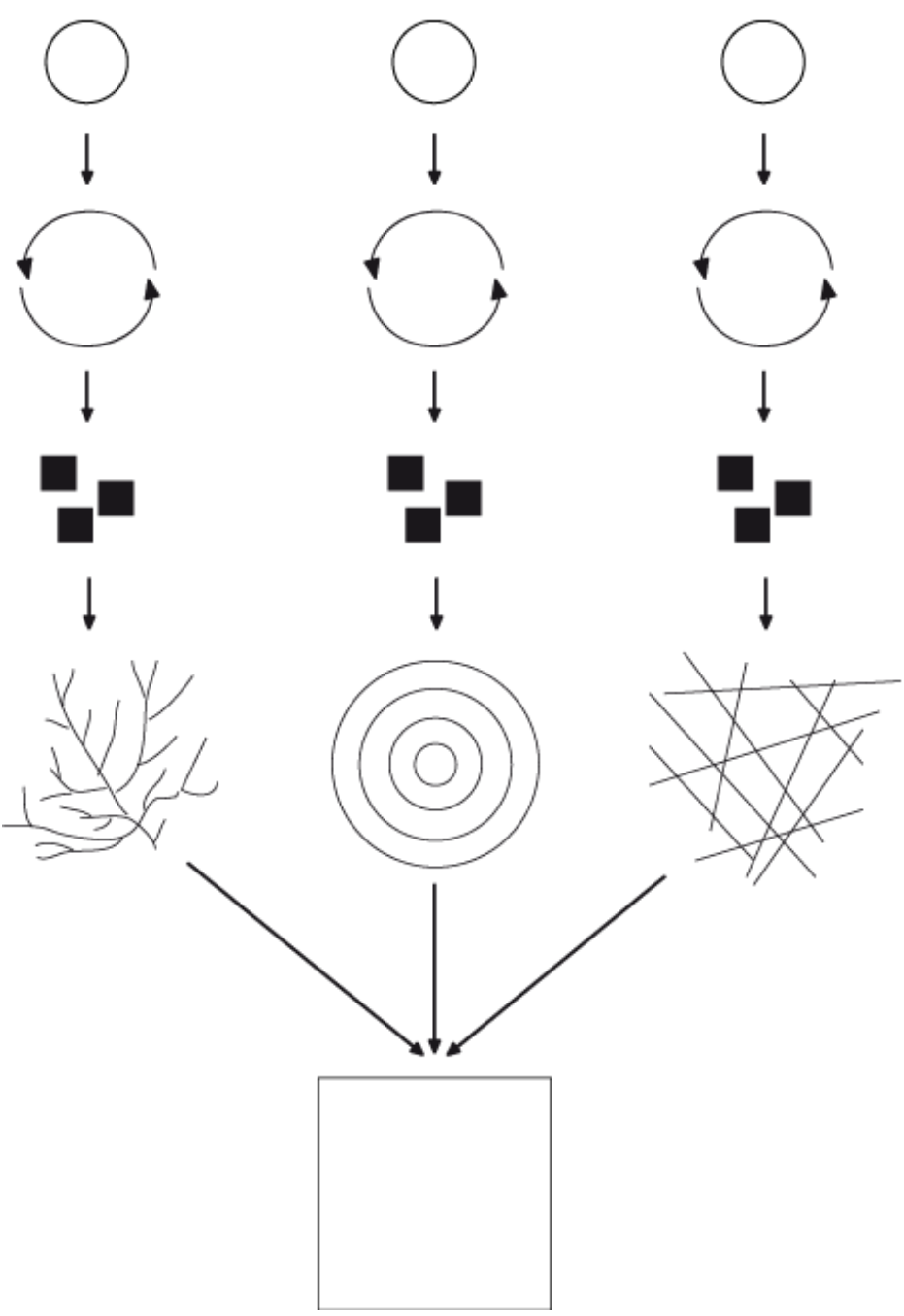

REALITY LEVEL

EMERGENT PROCESS LEVEL

DECONSTRUCTING LEVEL

VISUALIZATION LEVEL

INTERACTION STORYTELLING LEVEL

Figure 2. Sketch of the meta-design framework. 


\section{CONCLUSION}

In a previous study we identified three emergent city properties expressed through environmental transformations. In this paper we try to systematize the process of interpretation of the processes of emergence. So we have prefigured a tool that gives to the designers an approach or an attitude of meta-design by extracting city properties from the complexity, visualizing them and coming back again to the complexity of reality through the storytelling level.

Thanks to this approach, designers could empathize with the attributes of the emergent city properties, in order to find suitable solutions that meet the city (and citizen)'s needs expressed through these emergent properties.

This approach allows the designers to understand the processes of emergence and their attributes through the use of visualization tools, in order to "empathize" with the city.

This type of approach can help to figure out very complex systems, as cities, in which, as the Gestalt Theory says: "the whole is greater than the sum of its parts".

\section{RÉFÉRENCES}

Calvino, I. (1996). Le città invisibili. Oscar Mondadori, Italy.

Martinelli, F. (2004). Città e scienze umane: sociologie del territorio, geografia, storia, urbanistica, antropologia, semiotica, informatica. Liguori, Napoli.

Minati, G. (2001). Esseri collettivi. Sistemica, fenomeni collettivi ed emergenza. Apogeo Editore.

Minati, G. (2011). "Quale conoscenza per gestire la complessità della società della conoscenza e dei suoi processi?”. Riflessioni Sistemiche, 5:122-137.

Soddu C., Colabella E. (1992). The environmental design of morphogenesis. Progetto Leonardo Publisher.

Volpi V., Opromolla A., Grimaldi R., De Cecio V., Palatucci M., Medaglia C. M. (2015). "Thinking Smart City with a focus on emerging identity elements", Towards a Post-Bertalanffy Systemics, (Minati G., Abram M., Pessa E.), Springer, Gewerbestrasse (in press). 
